\title{
Integrated models of livestock systems for climate change studies. 1 . Grazing systems
}

\author{
D. J. PARSONS, A. C. ARMSTRONG*,J.R. TURNPENNYt, A. M. MATTHEWS , \\ K. COOPER t and * J. A. CLARK \\ *Silsoe Research Institute, Wrest Park, Silsoe, Bedford MK45 4HS, UK, †ADAS Gleadthorpe, Meden Vale, Mansfield, \\ Nottinghamshire NG20 9PF, UK, †Division of Environmental Science, School of Biological Sciences, University of Nottingham, \\ Sutton Bonington Campus, Loughborough, Leicestershire LE12 5RD, UK
}

\begin{abstract}
The potential impact of climate change by the year 2050 on British grazing livestock systems is assessed through the use of simulation models of farming systems. The submodels, consisting of grass production, livestock feeding, livestock thermal balance, the thermal balance of naturally ventilated buildings and a stochastic weather generator, are described. These are integrated to form system models for sheep, beef calves and dairy cows. They are applied to scenarios representing eastern (dry) lowlands, western (wet) lowlands and uplands. The results show that such systems should be able to adapt to the expected climatic changes. There is likely to be a small increase in grass production, possibly allowing an increase in total productivity in some cases.
\end{abstract}

Keywords: climate change, grass, integrated assessment, ruminants, buildings, physiology

Received 5 November 1999; revised version received 17 May 2000 and accepted 29 June 2000

\section{Introduction}

The impacts of climate change on agriculture can be both felt and studied at many scales. Parry et al. (1998) identify three orders of interactions: biophysical, enterprise and national. At the smallest scale, the changes to the thermal, hydrological and nutrient regime on plant physiology can be studied directly (Kimball 1983; Melillo et al. 1990). At the largest scale, the changes to the global economy will impact on the need for food and the location of food supplies. Practical agriculture lies between these two extremes. It grows plants, but is much more than just the growing of plants: it is concerned with the nurture, protection, and utilization of those plant products. It is affected by global economics, but to individual farmers these are external constraints, applied in terms of costs and prices.

The group of studies included in this and the companion paper (Turnpenny et al. 2000c) focus on the farm-level impacts of climate change, and so take both the physiological scale changes and the macroeconomic situation as the context within which the system functions. The aim is to examine the functioning of the

Correspondence: D. J. Parsons, fax $+44 / 1525860156$, e-mail david.parsons@bbsrc.ac.uk most basic agricultural unit, the farm. It differs from the approach taken by studies such as those, for example, Harrison (1996), UKCCIRG (1996) or Brignall et al. (1996), which have produced maps of crop possibilities for future climate scenarios, generated by assuming that the relevant crops may be grown at all locations. By contrast, analysis at the farm level examines the need to maintain the whole farm enterprise, the level at which decisions are taken within the possibilities defined by the climate and constrained by the economic context.

Interest is focused on livestock systems, which include both the production of the basic foodstuff, its utilization by the grazing animal, and then (in the companion paper) the issue of the welfare and productivity of housed animals. In all of these studies, the aim is to identify the degree to which agricultural practices and opportunities will change as the climate changes.

This study could, in principle, be applied to any or all locations in England and Wales. However, rather than attempt distributed implementations, it concentrates on three locations which were chosen to be typical of wide areas, and for which support data were available. These three sites were: 
- Boxworth, Cambridgeshire. Typical of the lowland areas of Eastern England.

- Cheshire plains. Typical of lowland milk producing areas.

- Pwilpeiren, Wales. This is representative of the upland situation.

The study could be implemented for any future scenario of climate change. It concentrated on the IPCC 92 scenarios, using the IS92a (business as usual) scenario for the year 2050. Tests showed that the predicted differences in impact between the IPCC 92 scenarios were small at this date. Larger timescales, which would cause significant differences, were inappropriate for this study.

\section{Limitations (self-imposed)}

It is clear that changes to the climate will affect the global economy and the price structure for agriculture. However, converting the current range of economic predictions into a set of costs that could be input into a model is outside the scope of this project. For this reason, the models adopted do not attempt to explore these changes, but instead assume that the current price structure for agricultural commodities will remain similar to prices today. (This is not to say that the prices will be constant, but that they will remain in the same relation one to another). The model developed, however, would be capable of exploring the effects of differing price structures, should a suitable set of inputs be defined. The virtue of changing only part of the model inputs (the climate) is that it allows the isolation of the effects of a single variable. This is the classical scientific method, and the results of the study can thus be viewed as the outcome of a numerical experiment rather than as prediction of the future.

By the same token, the study does not attempt to identify the effect of the changes of carbon dioxide concentration on either the radiation or the water use efficiency of the grass plants. To do so would have required parameterization of processes that were still the subject of basic research at the time the models were established. The magnitude of any effect would necessarily have been related to the anticipated carbon dioxide concentration in the atmosphere, for the relevant time for each of the six IPCC92 scenarios. Although Stockle et al. (1992) provide an algorithm for including this effect, they have not validated their approach for grass crops.

\section{Component models}

A schematic diagram of the integrated models is shown in Fig. 1. There are four main submodels:

1 Grass production, which predicts the growth of grass and the amount harvested for silage.
2 Livestock feeding, which predicts the intake of grass and concentrates, and calculates the metabolic heat production.

3 Animal heat balance, which predicts the thermal exchanges between the animals and their environment, and their physiological responses.

4 Building, which predicts the internal temperature and humidity of livestock buildings.

These models, together with the weather generator used to provide the data to drive them, are described below.

\section{Grass model}

The state of the grass crop is simulated by the SWARD (Soil Water And Response to Drainage) model (Armstrong etal. 1995). This model was developed by Dowle \& Armstrong (1990) in the context of the North Wyke drainage experiment (Armstrong \& Garwood 1991; Tyson et al. 1993), and has been subsequently used for climate change impact studies (Armstrong \& Castle 1992, 1995; Armstrong 1996).

The SWARD model simulates, in parallel, the water balance for the soil and the herbage weight in the grass sward. The model considers the soil as a single store to which water is added as rainfall and removed by evapotranspiration and (if relevant) by drainage. Two important soil parameters are thus the moisture content at which crop stress begins (wilting point, WP) and the content at which transpiration and growth cease (permanent wilting point, PWP). Between WP and PWP the actual rate of evapotranspiration is reduced in proportion to the stress. Water may be stored in excess of field capacity, up to the total porosity of the soil. If the soil is drained, this water drains from the profile at a rate calculated from the Hooghought drainage equation (Ritzema 1994). Water is removed from the profile only by drainage or evapotranspiration, so the model is applicable to clay soils, rather than freely draining soils.

The state of the grass sward is modelled by a balance equation. Grass is added by growth, and removed by senescence and harvesting (cutting or grazing). The rate of senescence is dependent on temperature and herbage weight (Dowle \& Armstrong 1990), and the rate of grass growth $\left(G_{\text {act }}\right)$ is defined by a maximum potential rate $\left(G_{\max }\right)$ multiplied by a series limiting functions which take values between 0 and 1

$$
G_{\text {act }}=G_{\max } f(J W) f(N) f(T) f(B),
$$

where $G_{\max }$ is a physiological constant, depending on the nature of the sward. For ryegrass swards in UK a value of $250 \mathrm{~kg} \mathrm{ha}^{-1} \mathrm{~d}^{-1}$ has been reported (Parsons \& Johnson 1985). 


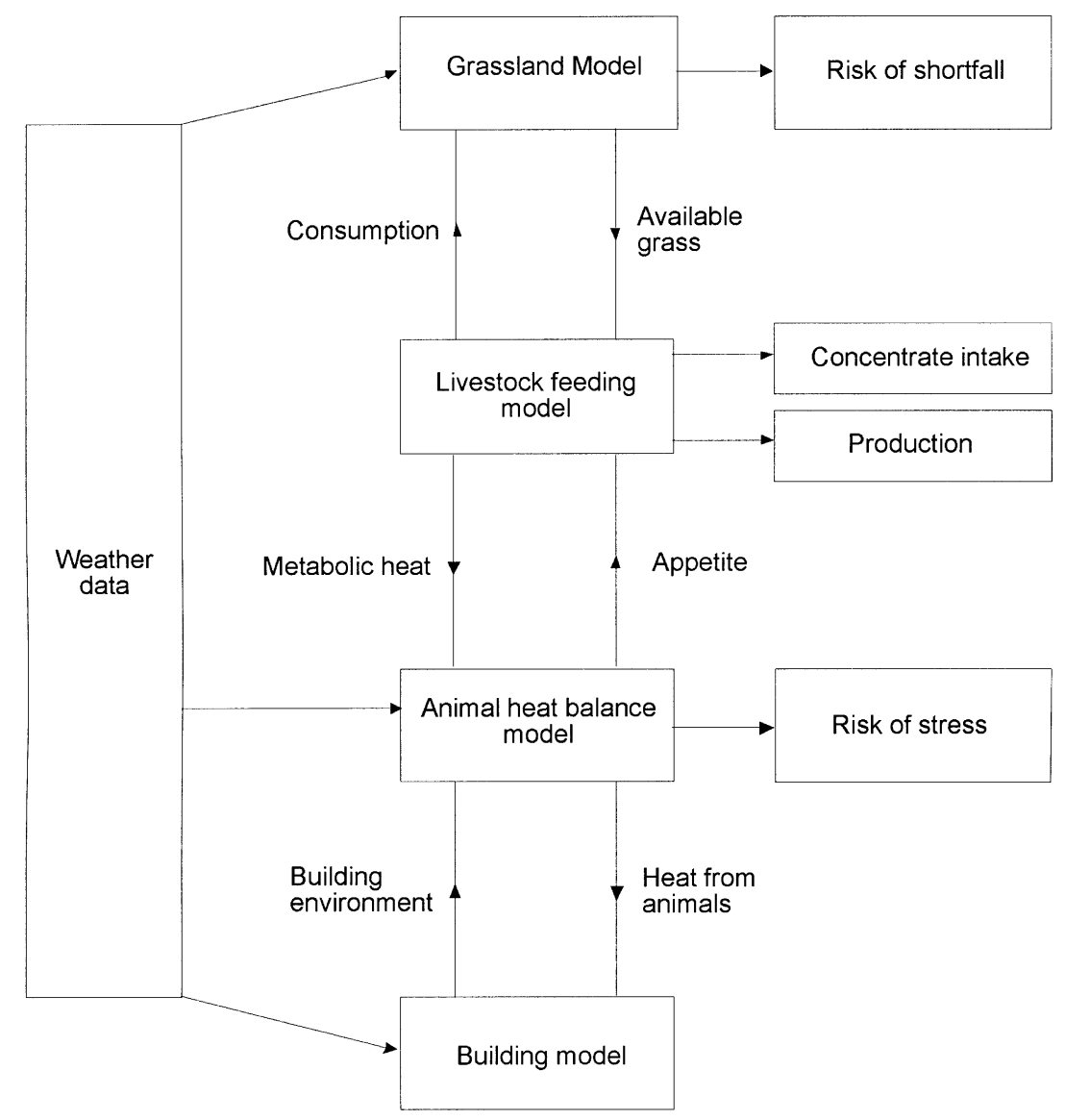

Fig. 1 Schematic diagram of the grazing animal integrated model.

For this study, the nitrogen response, $f(\mathrm{~N})$ is assumed to be nonlimiting, i.e. the sward always has adequate nutrition. The temperature response function, $f(T)$, is taken to be linear between 5 and $20^{\circ} \mathrm{C}$, above which it is nonlimiting. No growth is assumed to take place in any year until the temperature sum reaches 200 day ${ }^{\circ} \mathrm{C}$ above 0 , from 1st January.

The rate at which a grass crop can intercept radiation is a function of the leaf area index for which the crop weight is used as a proxy. When radiation is nonlimiting, the growth rate, $f(W)$ depends on the crop weight:

$$
\left.f(J W)=f(W)=1-\left\{W-W_{\mathrm{opt}}\right) / W_{\mathrm{opt}}\right\}^{2},
$$

where the optimum crop weight, $W_{\text {opt }}$ is $5 \mathrm{tha}^{-1}$ (Dowle \& Armstrong 1990). When crop weight is nonlimiting, but radiation is limited, the radiation limitation, $f(J)$ is given by a similar function:

$$
f(J W)=f(J)=1-\left\{\left(J-J_{\mathrm{opt}}\right) / \mathrm{opt}\right\}^{2} .
$$

When both are limiting, $f(J W)$ is the product of $f(J)$ and $f(W)$. Grazing or cutting reduces the photosynthetic efficiency of the crop, by reducing the crop weight, hence the need to include utilization as a component of SWARD. The inclusion of crop removal in SWARD ensures that grass management is an integral part of the model, which makes it ideal for inclusion in the integrated grass growth and utilization model required for this work.

Grass growth is limited both by water in excess (water logging) and by water shortage (drought) expressed as a function $f(B)$. The rate of growth is unlimited between field capacity and wilting point, but declines linearly outside these bounds, ceasing completely at both saturation and PWP. The interaction between grass growth rate and water shortage mirrors the reduction in actual evapotranspiration, and the model thus explicitly links the growth of grass to transpiration rate.

The quality of herbage is estimated using the model described by Edelsten \& Corrall (1979). Digestibility of 
cut sward harvested on day $i$ is predicted from the equation:

$$
D=73.6+2.5 \sin \frac{2 \pi i}{365}+1.6 \cos \frac{2 \pi i}{365}-0.018 j-0.715 y_{h}
$$

where $D$ is the digestible organic matter (\% of total dry matter), $j$ is the number of days since the previous harvest, and $y_{\mathrm{h}}$ is the amount at the previous harvest ( $\mathrm{t}$ $\mathrm{ha}^{-1}$ )

A similar model of sward quality was not available for grazed swards. However, data from the North Wyke grazing experiment (Tyson etal. 1993) showed similar patterns to those predicted by the Edelsten \& Corrall equation. Because the modelled swards included a mixture of both grazing and cutting, the Edelsten \& Corral relationship was used throughout, in order to preserve a consistent estimate of digestibility values throughout the year. No attempt has been made to predict the effects of either temperature or drought on forage digestibility. The reduction in forage quality and palatability resulting from a change in the carbon to nitrogen ratios reported by Allen-Diaz (1996) affected low-latitude rangelands, and are thought not to be a problem for UK grassland, and so is not considered here.

\section{Livestock feeding models}

All the ruminant feeding models concentrate on energy metabolism using the factorial approach (AFRC 1993). The total intake is calculated as a function of the diet digestibility and the animals' liveweight and (for dairy cows) milk yield. This typically has the form

$$
x=a w^{0.75},
$$

where $x$ is intake $\left(\mathrm{kg} \mathrm{DMd} \mathrm{d}^{-1}\right), w$ is liveweight $(\mathrm{kg})$ and the coefficient $a$ increases with digestibility.

The total metabolizable energy requirement, $E\left(\mathrm{MJ} \mathrm{d}^{-1}\right)$ is the sum of the components

$$
E=\Sigma E_{i}=\Sigma e_{i} / k_{i}
$$

where the components are maintenance, growth, pregnancy and lactation, denoted by subscripts $\mathrm{m}, \mathrm{g}, \mathrm{p}$ and $\mathrm{l}$, respectively. The coefficients $k_{i}$ are the empirically derived conversion efficiencies from metabolizable energy in the feed to energy deposited or utilized by the animal. If the total energy intake exceeds the requirement, the rate of weight gain is increased and conversely provided the metabolic requirements (maintenance, pregnancy and lactation) are met. If the intake is insufficient to meet the metabolic requirements, that is all except growth, fat reserves will be mobilized to supply the shortfall.

The energy deposited as body tissue, foetal tissue and milk is considered to be retained. The rest forms the metabolic heat production $Q$ :

$$
Q=E_{\mathrm{m}}+E_{\mathrm{g}}\left(1-k_{\mathrm{g}}\right)+E_{\mathrm{p}}\left(1-k_{\mathrm{p}}\right)+E_{\mathrm{l}}\left(1-k_{\mathrm{l}}\right) .
$$

The beef calf and lamb models consider only maintenance and growth. In the case of the lamb, the model includes the transition from milk to grass, whereas the beef calf is assumed to be weaned and grown from $50 \mathrm{~kg}$ to about $500 \mathrm{~kg}$ over a period of up to two years on a grass and concentrates diet.

The ewe and the dairy cow models both include pregnancy and lactation because they represent significant energy demands in certain periods. The energy required for lactation $E_{1}$ is assumed to be proportional to the milk yield. In the case of the dairy cow, lactation follows a standard curve (Wood 1969), whereas for the ewe it is determined by the requirements of her offspring. The requirement for pregnancy (development of the placenta and foetus) follows a Gompertz curve.

\section{Thermal model for ruminants}

Knowledge of the thermal status of livestock, and the interaction between animal and environment, is essential for the formulation of any model of a livestock system. The general effects of weather conditions on the thermal balance of animals are well documented. Low temperatures, high winds or wetting of the animal reduce the growth rate (Close 1987) and the feed intake required for maintenance increases (Thompson 1973). Combinations of cold and wet conditions can cause death from hypothermia (e.g. Glass \& Jacob 1991). Hot weather also has adverse effects. Heat stress reduces feed intake and the digestibility of the food (Bianca 1965), depresses milk production, affects the ovulation cycle and increases embryo mortality (Bianca 1965; Close 1987). The water requirement also increases. In addition to adversely affecting economic productivity, the animal's welfare suffers under thermal stress.

There are several models in existence dealing with the energy balance of homeotherms (e.g. Bruce \& Clark 1979; Stafford Smith etal. 1985; McArthur 1987; Higgins \& Dodd 1989). Most are either simple empirical models with meteorological data as inputs, or more detailed mechanistic models with idealized inputs. The aim of the current work was to combine these two approaches and produce a physically based model based on established principles of energy transfer and animal physiology. The principal outputs are the energy requirement for a specified hourly period, and a quantification of the 
degree of thermal stress suffered, given the meteorological conditions.

The model was developed to predict the heat loss from a single animal, in steady state under specified meteorological conditions, Turnpenny etal. (2000a,b). The ruminant model was based on a system of round-ended cylinders with a layer of outer insulation to represent the coat (McArthur \& Monteith 1980). This model consisted of a core producing heat and demanding feed energy, surrounded by three layers: the peripheral tissue, the coat and the outside environment. Because the feed model fixes the metabolic rate, the heat balance of the animal was solved assuming no heat was stored in any of the three layers. The total energy flux through each layer is therefore equal in a steady state, by the law of conservation of energy. Thus the heat balance for the cylinder can be written as:

$$
\begin{aligned}
& \text { Energy Loss From Each Part }= \\
& \text { Conduction Through Tissue }=
\end{aligned}
$$

Coat Transfer + Surface Evaporation $=$

Convection + Thermal Radiation + Evaporation-

Solar Radiation

The heat transfer through each layer can be written in terms of a simple Ohm's Law analogy, which relates heat flux density to temperature difference:

heat flux density $\propto$ (temperature difference)/resistance.

Heat flux density has units of $\mathrm{W} \mathrm{m}^{-2}$, and is obtained by dividing the heat flux by the area over which heat transfer takes place. For the model the appropriate surface is the skin surface area of the body. Thermal resistance has units of $\mathrm{s} \mathrm{m}^{-1}$. The constant of proportionality is the volumetric specific heat of air, which is about $1220 \mathrm{~J} \mathrm{~m}^{-3} \mathrm{~K}^{-1}$ at $20^{\circ} \mathrm{C}$ (Gates 1980). The energy balance equation (8), was solved using iteration to calculate the temperatures at the layer interfaces (skin and coat surfaces), the resistance to each transfer process through each layer, and hence the total heat loss from the animal.

For outdoor animals, solar radiation, rainfall and wind speed are all important weather inputs. Solar radiation absorbed by animals can exceed four times maintenance thermoneutral heat production (Clapperton et al. 1965), while a thoroughly wet coat can decrease the external resistance of the animal to heat transfer by up to $30 \%$ (Mount \& Brown 1982; McArthur 1991). A strong wind can penetrate the deepest coat, reducing its insulation substantially. The parameterizations of these weather variables in the thermal balance model are discussed in detail in Turnpenny (1997).

In the thermoneutral zone, an animal has to dissipate a minimum amount of heat, produced by metabolization of its food intake (Mount 1979; Parsons 1993). If the environmental demand for heat is greater or less than the thermoneutral metabolic heat production, homeotherms must employ physiological and/or behavioural methods to balance heat loss with the metabolic rate, and thus preserve homeothermy.

In hot conditions the environmental demand is less than the thermoneutral heat production. The animal must then increase the heat loss to the environment. One method employed is vasomotor control of peripheral blood flow. Other mechanisms to enhance heat loss are panting, which increases the evaporative heat loss from the respiratory tract, and sweating, which increases evaporative heat loss from the skin. Experimental data and analysis indicate that animals regulate sensible heat loss (i.e. convection and radiation) in preference to evaporative heat loss. The implication is that an animal will use vasomotor control before panting, as increasing evaporative loss involves loss of water and, at high rates of panting, an increase in metabolic rate. These are both costly to the animal. In the current thermal balance model, vasomotor control of blood flow is parameterized by allowing a variable tissue resistance in the legs of the sheep and trunk of the cow (Blaxter etal. 1959). The resistance value was chosen by the model to force heat loss to equal heat production. When blood flow is at a maximum, the sheep model used panting to dissipate the excess heat loss (Alexander 1974). The respiration rate was calculated from empirical equations derived from data in Hales \& Webster (1967). The cow uses sweating rather than panting to dissipate excess heat, and latent heat loss from the skin was increased accordingly in the model.

When heat loss to the environment is greater than the thermoneutral metabolic heat production, homeotherms will respond by increasing metabolic rate (e.g. by shivering or movement). Shivering decreases the tissue resistance by up to $30 \%$ (Blaxter et al. 1959), but the benefit from increasing the heat production (by up to six times the thermoneutral value in humans (Parsons 1993)) outweighs the decrease in resistance. Shivering is parameterized in the model by reducing the tissue resistance of the trunk from the thermoneutral value (taken as $100 \mathrm{~s} \mathrm{~m}^{-1}$ ) to a value which maintains energy balance. Maximal shivering is assumed to occur when the tissue resistance is $70 \%$ of the thermoneutral level (Blaxter et al. 1959). In very cold conditions, vasomotor control is used to prevent freezing of the tissue of the extremities. If the skin temperature of the leg or head 
falls below $5^{\circ} \mathrm{C}$, the tissue resistance will fall to maintain the skin temperature at $5^{\circ} \mathrm{C}$.

\section{Thermal balance model for naturally ventilated buildings}

In the UK, most livestock are housed either periodically or year-round in livestock buildings in order to manage them better and protect them from the weather. In order to assess the effect of climatic change on grassland and livestock systems accurately we must therefore model the animals' interaction with their housing. Unsuitable microclimates may result in thermal stress of the animals, with consequent losses in production and risks to welfare. In the main, pigs and poultry are housed in controlled environment buildings whilst sheep and cattle are periodically housed in naturally ventilated buildings.

Naturally ventilated buildings are generally poorly insulated, with part of their walls open. Thus ventilation consists of thermally induced and wind-driven components. There are many different types of these buildings and many specific buildings have been modelled in the past (for example, Bruce 1974). We wished to keep the model as general as possible whilst still giving realistic representations of the buildings' mean internal temperature. The model calculates steady-state heat balances every hour, combining estimates of wind, thermal buoyancy effects and solar radiation based on established work cited below.

The model is based on the heat balance equation (Charles 1981),

$$
Q=c V \Delta T+U A \Delta T
$$

where $Q$ is the sensible heat output per animal $(\mathrm{W})$; $c$ is the volumetric heat capacity of air $\left(\mathrm{J} \mathrm{m}^{-3} \mathrm{~K}^{-1}\right) ; V$ is the ventilation rate per animal $\left(\mathrm{m}^{3} \mathrm{~s}^{-1}\right) ; U$ is the average thermal transmittance of walls and roof $\left(\mathrm{W} \mathrm{m}^{-2} \mathrm{~K}^{-1}\right)$; $\mathrm{A}$ is the exposed area of walls and roof per animal $\left(\mathrm{m}^{2}\right)$; and $\Delta T$ is the temperature lift above the external temperature (K). The sensible heat output of the animal is calculated in the feeding model described above.

The ventilation term in the above equation is a combination of wind-forced ventilation and buoyancy effect ventilation, caused by differences in internal and external pressure (Cooper et al. 1998). For simplicity, the turbulent effect of air entering is ignored and we assume that air only enters by the windward walls.

All the building surfaces are heated by radiation and cooled by convection. The intensity of the radiation on any surface will depend upon the angle of incidence of the sun's rays and the observed radiation. The model calculates the direct and diffuse radiation on each of the surfaces of the building. The contributions of radiation and convection are combined in the 'sol-air temperature' (Owen 1994). If the net radiation on the surface of the building wall is sufficiently high, the surface of the building will conduct this net heat flux through the wall into the building.

Under the steady-state assumption, the resulting total flux at the surface of the building is equal to the conduction term in (10), so may be substituted for it. The result is a cubic equation for the temperature rise in terms of the weather variables, which may be solved analytically, avoiding the need for numerical solution of a system of nonlinear equations. This model has been tested for a typical calf house and found to give a good prediction of the hourly mean internal temperature. (Full details in Cooper et al. 1998.)

\section{Weather generators}

In order to apply the models, it is necessary to have long and realistic sequences of meteorological data. Although these could be derived from current meteorological records for the present climate, the required data cannot in principle be so derived for the future. Some scheme must be chosen to generate plausible weather data for future climates.

Of the various possibilities, the use of a stochastic weather generator was adopted. This gives the flexibility of generating virtually infinite sequences of weather data for any scenario, including the current climate. In order to maintain comparability, the same weather generator must be used for both current and changed climates. Figure 2 shows a schematic representation of the weather generator.

The scheme for deriving the data consists of three parts:

1 The estimation of current climatic parameters for input into the weather generator. Detailed meteorological observations recorded at eight ADAS experimental sites throughout UK were used to define the monthly means and distribution statistics for the EPIC weather generator (Richardson \& Nicks 1990), using the program imported and modified from the EPIC package (Sharpley \& Williams 1990).

2 Spatially variable estimates of climate means were extracted from UK baseline climatology and for climate change scenarios within the SPECTRE package using the UKHI global circulation model results and 'medium' $\mathrm{CO}_{2}$ sensitivity (Barrow et al. 1994) on a $10^{\prime}$ resolution. Data are available for the six IPCC 1992 scenarios and the UK Met Office transient dataset up to the year 2100. The dataset consists of the following variables on a monthly basis: maximum temperature, minimum temperature, mean temperature, diurnal temperature range, precipitation, incident solar radiation, vapour pressure and wind 


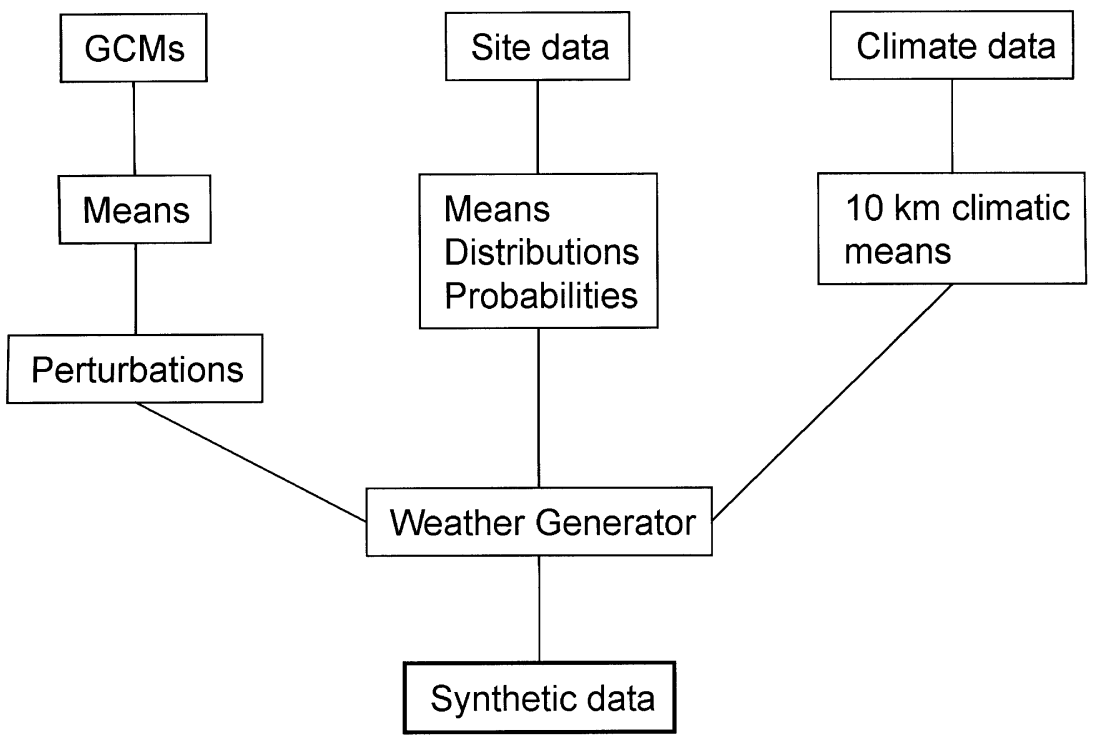

Fig. 2 Overview of the weather generator system.

speed. Changes in the other parameters of the climate (such as the transition parameters for the rain day Markov chain) which are currently not available from the GCM models, are taken unchanged from the analysis of current data.

3 These sources of data are integrated by the EPIC daily weather generator (Richardson \& Nicks 1990) which is itself derived from Richardson (1981). Each section of the generator has a local mean value defined from the baseline climatology, a perturbation component derived from SPECTRE and a set of distribution and transition parameters derived from the current dataset.

In the weather generator, the defining stage of generating weather sequences is the establishment of a first-order Markov chain describing the sequence of rain days. On each wet day the precipitation amount is sampled from a skewed normal distribution. Maximum and minimum daily temperatures are generated as residuals from the monthly means using the weekly stationary generating process of Matalas (1967). The wind speed component is generated from a twoparameter gamma distribution; the vapour pressures from a triangular distribution; and wind direction from the probabilities compiled for each month. The set of values is then input into a Penman-Monteith equation to calculate daily reference evapotranspiration $\left(E T_{0}\right)$.

Although the EPIC generator has been used successfully for many studies in the USA, its applicability to the UK is less certain. It is included in the SSLRC SEISMIC database system (Hallett etal. 1992; Hollis et al. 1993). However, it has been observed that although it predicts
Table 1 Annual mean temperature and rainfall for baseline and climate change scenarios

\begin{tabular}{|c|c|c|c|c|c|c|}
\hline & \multicolumn{2}{|c|}{ Boxworth } & \multicolumn{2}{|c|}{ Cheshire } & \multicolumn{2}{|c|}{ Pwllpeiran } \\
\hline & $\begin{array}{l}\text { Temp. } \\
{ }^{\circ} \mathrm{C}\end{array}$ & $\begin{array}{l}\text { Rainfall } \\
\mathrm{mm}\end{array}$ & $\begin{array}{l}\text { Temp. } \\
{ }^{\circ} \mathrm{C}\end{array}$ & $\begin{array}{l}\text { Rainfall } \\
\mathrm{mm}\end{array}$ & $\begin{array}{l}\text { Temp. } \\
{ }^{\circ} \mathrm{C}\end{array}$ & $\begin{array}{l}\text { Rainfall } \\
\mathrm{mm}\end{array}$ \\
\hline Baseline & 9.6 & 564 & 8.8 & 868 & 8.1 & 1777 \\
\hline $2050 a$ & 10.8 & 610 & 10.0 & 950 & 9.2 & 1940 \\
\hline $2050 c$ & 10.6 & 604 & 9.8 & 938 & 9.1 & 1916 \\
\hline $2050 \mathrm{f}$ & 11.0 & 616 & 10.1 & 960 & 9.4 & 1959 \\
\hline
\end{tabular}

the means of rainfall distributions quite well, it underpredicts the frequency of rare events such as the highintensity rainfalls that might generate erosion events (Favis-Mortlock 1995).

The generated daily values are subsequently scaled down to hourly values (Turnpenny 1997). Air temperature, precipitation, direct and diffuse solar radiation, radiant temperature of the sky and ground temperature are calculated from the daily values using empirical relationships. Vapour pressure, wind speed and wind direction are assumed constant over the day.

Table 1 shows the annual mean temperature and rainfall for each site currently and as predicted by the climate change models for three scenarios for the year 2050. These scenarios are taken from the report of the Intergovernmental Panel on Climate Change (IPCC 1992) and represent 'business as usual' (IS92a), low economic 
Table 2 Monthly mean temperature and rainfall for Boxworth for baseline and IS92a

\begin{tabular}{|c|c|c|c|c|c|c|c|c|c|c|c|c|}
\hline & Jan & Feb & Mar & Apr & May & Jun & Jul & Aug & Sep & Oct & Nov & Dec \\
\hline \multicolumn{13}{|c|}{ Temperature $\left({ }^{\circ} \mathrm{C}\right)$} \\
\hline Baseline & 3.4 & 3.2 & 6.2 & 7.7 & 10.9 & 14.1 & 16.6 & 16.5 & 14.2 & 10.7 & 6.7 & 4.9 \\
\hline $2050 a$ & 5.0 & 5.0 & 7.7 & 8.8 & 12.2 & 15.1 & 17.6 & 17.6 & 15.4 & 11.7 & 7.6 & 6.1 \\
\hline \multicolumn{13}{|c|}{ Rainfall (mm) } \\
\hline Baseline & 45.6 & 31.6 & 46.6 & 45.4 & 49.4 & 54.7 & 45.1 & 51.3 & 46.5 & 54.7 & 44.9 & 48.2 \\
\hline $2050 a$ & 53.9 & 35.3 & 53.5 & 49.6 & 53.0 & 58.7 & 45.3 & 53.3 & 47.4 & 59.4 & 46.8 & 53.9 \\
\hline
\end{tabular}

Table 3 Cutting and grazing routine for beef calf

\begin{tabular}{|c|c|c|c|c|c|c|c|}
\hline \multicolumn{4}{|c|}{ Year 1} & \multicolumn{4}{|c|}{ Year 2} \\
\hline Day & $\begin{array}{l}\text { Field } \\
1\end{array}$ & $\begin{array}{l}\text { Field } \\
2\end{array}$ & $\begin{array}{l}\text { Field } \\
3\end{array}$ & Day & $\begin{array}{l}\text { Field } \\
1\end{array}$ & $\begin{array}{l}\text { Field } \\
2\end{array}$ & $\begin{array}{l}\text { Field } \\
3\end{array}$ \\
\hline 1 & & & & 1 & & & \\
\hline 110 & G & & & 110 & G & & \\
\hline 150 & & C & C & 125 & $S$ & G & C \\
\hline 200 & & $\mathrm{C}$ & $\mathrm{C}$ & 150 & G & $\mathrm{S}$ & $\mathrm{C}$ \\
\hline 220 & & & C & 180 & $S$ & G & $\mathrm{C}$ \\
\hline 246 & $S$ & G & & 246 & G & S & \\
\hline 255 & & & $\mathrm{C}$ & 250 & & & $\mathrm{C}$ \\
\hline 264 & & $S$ & & 264 & $S$ & & \\
\hline
\end{tabular}

G, start grazing; S, stop grazing; $\mathrm{C}$, cut grass for silage

growth (IS92c) and high economic growth (IS92f). The differences between the three scenarios are small by this date. It is only towards the end of the next century that the differences between scenarios become significant. Table 2 shows the monthly means used in the calibration of the weather generator. These are shown for Boxworth only to illustrate the seasonal pattern of the changes. They show an increase both in temperatures and rainfall amounts.

\section{Integrated model}

\section{Model structure}

In order to evaluate the performance of livestock systems under future climatic scenarios the individual submodels need to be combined. The interaction between the models is shown in Fig. 1. At the start of each day the grass growth and the animals' intake requirements of concentrates and grass or silage are calculated, and the appropriate forage pool is adjusted appropriately. Forage shortages are recorded as an indicator of potential problems. The metabolic heat production, treated as a constant for the day, is calculated and fed to the animal heat balance model. The other inputs to this model come from the weather, if necessary modified by the building heat balance model. Both of the heat balance models operate on an hourly time step, and calculate the thermal balance, including stresses experienced throughout the day.

Heat stress in animals reduces their appetite and consequently their food intake. This may lead to a reduction in milk yield, reproductive efficiency, and increased embryo mortality in the dairy cow and ewe. The lamb and beef calf will grow at a slower rate if stressed. There are few detailed experimental studies of the effects of periods and degrees of heat stress that are suitable for this model. Studies in which animals were exposed to high levels of stress for several hours per day, for example Senft \& Rittenhouse (1985), show reductions in intake of up to $15 \%$. For the purposes of the model it was assumed that intake was reduced by $2 \%$ for each hour of severe stress, up to a maximum of $16 \%$. The metabolic energy available for growth is consequently reduced for the beef calf and lamb. For the ewe and dairy cow it is slightly more complicated as the animal may be using energy for pregnancy or lactation, as well as maintenance and growth. The loss in metabolic energy is allocated in the following order: (i) the energy for lactation is reduced; (ii) the energy for growth is reduced; (iii) the energy for pregnancy is reduced; and (iv) the animal loses weight.

The sheep model runs for one year from 1st January to 31st December, the dairy cow model includes an additional run-in period for the grass model only from 1st January until the start of grazing, then runs for a year, and the beef calf typically takes 18 months to 2 years to reach a mature weight.

\section{Inputs to ECCLIPS}

ECCLIPS (Effect of Climate Change on Livestock Production Systems) uses the inputs defined for all the component models. The main inputs are as follows:

System model: Weather dataset, year, duration of run

Grass model: Number of fields, minimum grazing height, wilting point, field capacity, initial quality and yield 
Table 4 The effect of site and season on the length of the grazing season and the duration of wilting

\begin{tabular}{|c|c|c|c|c|c|c|c|}
\hline \multirow[b]{2}{*}{ Site } & \multirow[b]{2}{*}{ Scenario } & \multicolumn{3}{|c|}{ Grazing season (d) } & \multicolumn{3}{|c|}{ Wilting duration (d) } \\
\hline & & Min. & Mean & Max. & Min. & Mean & Max. \\
\hline \multirow[t]{2}{*}{ Boxworth } & Baseline & 142 & 224 & 244 & 58 & 141 & 214 \\
\hline & $2050 a$ & 185 & 226 & 244 & 59 & 142 & 211 \\
\hline \multirow[t]{2}{*}{ Cheshire } & Baseline & 130 & 175 & 214 & 0 & 66 & 139 \\
\hline & $2050 a$ & 131 & 176 & 212 & 0 & 69 & 140 \\
\hline \multirow[t]{2}{*}{ Pwllpeiran } & Baseline & 122 & 123 & 141 & 0 & 4 & 73 \\
\hline & $2050 \mathrm{a}$ & 122 & 123 & 141 & 0 & 3 & 70 \\
\hline
\end{tabular}

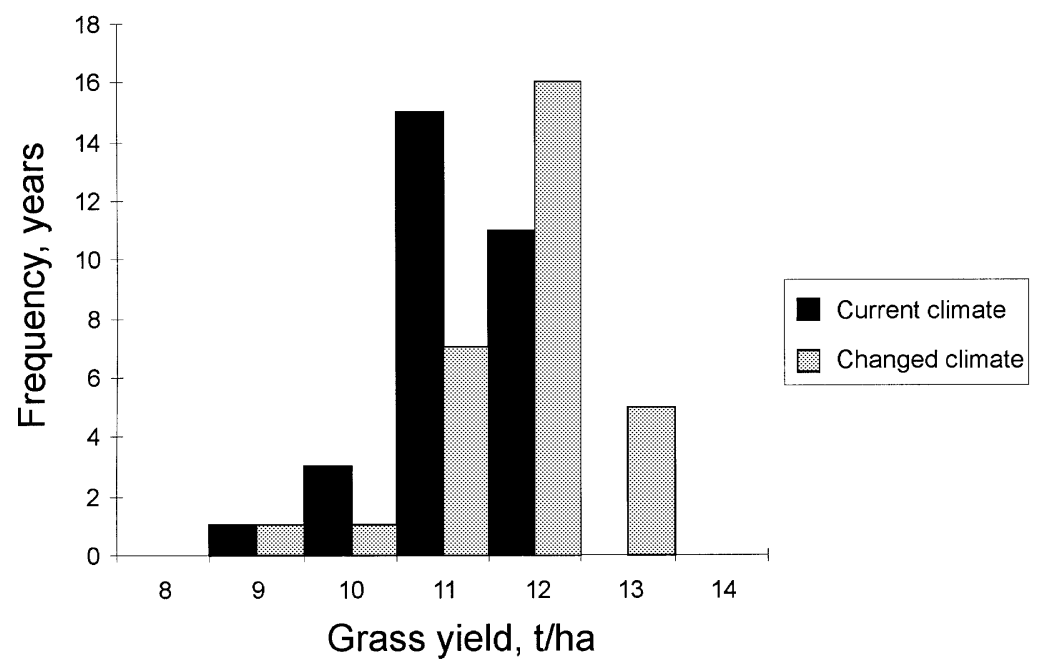

Fig. 3 Distribution of grass dry matter yields for dairy cows at Boxworth under present and changed climates.

Building model: Dimensions and orientation of building, $U$-values of walls and roof

Thermal balance model: Length of coat hair, latitude, tissue conductivities

Animal feeding model: Number of animals, number of young, calving (lambing) date, initial live weight, target weight

For all the grazing animals, ECCLIPS controls the management of the herd by using a cutting and grazing routine. This includes the number of fields and the dates to cut for silage, start and end grazing for each field. The dairy cow and beef calf are brought out and returned to housing according to the cutting and grazing routine. The calving pattern for the dairy cow can be set to simulate different systems; this study assumed calving at the beginning of September. A typical cutting and grazing routine for the beef calf, which may be kept for up to 24 months, is shown in Table 3.

\section{Output}

All the component models provide yearly and daily output. The yearly output provides 'risk' and 'produc- tivity' variables. These outputs are yield, intake, final weight, buffer feed requirement, frequency of stress and number of hours the ventilation system is unable to keep the internal temperature within the animals' thermoneutral zone. The buffer feed requirement is the shortfall in feeding when the available silage (in the winter) or the grass on the fields (in the summer) is insufficient.

\section{Computing aspects}

The programs were written in fortran for the Microsoft MSDOS $^{\mathrm{TM}}$ operating system, with a graphics program written for Microsoft Windows ${ }^{\mathrm{TM}}$ used to display the results. This combination allows batches of runs to be carried out automatically for subsequent analysis. The programs use files for all their input and output, so no intervention is required. The main input file is specified on the command line, and is structured in the same way as Windows INI files, containing named section for the general data and the inputs to each of the component models. Within these sections, variables are specified in the form name=value, which makes them easy to read and edit. To facilitate the use of combinations of standard 
Table 5 Main input variables for beef scenarios

\begin{tabular}{llll}
\hline & Boxworth & Cheshire & Pwllpeiran \\
\hline Number of calves & 240 & 240 & 180 \\
Duration of model run (d) & 550 & 550 & 550 \\
Initial liveweight $(\mathrm{kg})$ & 50 & 50 & 50 \\
Target liveweight $(\mathrm{kg})$ & 400 & 400 & 400 \\
Total grass area (ha) & 60 & 60 & 60 \\
Fertilizer applied $\left(\mathrm{kgN} \mathrm{ha}^{-1}\right)$ & 200 & 200 & 200 \\
\hline
\end{tabular}

scenarios, the sections can be placed in separate files, with their names given in the main input file, so, for example, one building file can be used with several different types of livestock. Additional command line arguments specify the weather data site, the IPCC scenario and the year to simulate. One set of input files can thus be applied to a range of meteorological scenarios and several years by using a batch command file. The output files available include complete sets of daily and hourly results from the component models, and annual summaries for complete sets of runs.

\section{Results}

Results are presented for each of the enterprise types in a common format: a table of the main variables that describe the systems, a table of the main performance measures, and a discussion of the main points. More detailed results for the dairy and beef systems are presented graphically; the sheep systems showed generally the same pattern as beef, but with smaller year-toyear variations. The graphs show the gross margin, heat stress and yield of primary product for all the years in the simulation, ranked by the value of the dependent variable for each scenario. These are similar to the stochastic dominance plots commonly used in decision analysis, in which cumulative frequency is plotted against the measure of performance (i.e. the transpose of the axes used here). It provides an informative comparison of the differences between two series in which the inherent variability is large and there are no meaningful paired samples. If one line lies always above the other, it may be said to dominate it, in the sense that any given value of the variable will be exceeded more frequently in that series than the other. It also provides a clear visualization of how frequently a given value is exceeded, which is particularly relevant when considering heat stress. In addition to the results for the individual enterprises, there is a more detailed discussion of the likely effects of climate change on grassland systems generally. The results are shown for scenario IS92a in the year 2050 only, because it was found that the variation in impacts between scenarios a, $c$ and $f$ was always negligible, as would be expected from the small differences in climatic data in Table 1 . The gross margin calculations use current prices to represent the financial situation if there were no changes in the relative prices of all inputs and outputs. In order to use a consistent set of commodity prices, the prices for beef are those prior to the depression in the market caused by measures to control BSE in the UK, and other recent falls in agricultural commodity prices.

As far as possible the farming scenarios were chosen to reflect typical current farming practice, and the model generally gave realistic gross margins for the baseline conditions. However, there were a few cases where it was not possible to achieve this and compromises had to be made. This was usually because of problems in matching the inputs and outputs of the feeding and thermal balance models: there is little recent experimental work, and none in which both aspects were studied in detail. Most of the data used in developing and testing the thermal balance model therefore reflect lower growth rates or yields than would be expected today. The stocking rates were not changed between the baseline and 2050a scenarios, although the grass yields often changed. Instead, the stocking rate with the baseline climate was set to require buffer feeding with externally produced forage in some years (included as a variable cost). Productivity changes are thus detected as changes in the requirements for buffer feeding.

Table 6 Performance measures for beef scenarios [mean (SD)]

\begin{tabular}{|c|c|c|c|c|c|c|}
\hline & \multicolumn{2}{|l|}{ Boxworth } & \multicolumn{2}{|l|}{ Cheshire } & \multicolumn{2}{|l|}{ Pwllpeiran } \\
\hline & Baseline & IS92a & Baseline & IS92a & Baseline & IS92a \\
\hline Final weight (kg) & $407(3)$ & $403(3)$ & $419(5)$ & $417(4)$ & $375(5)$ & $372(14)$ \\
\hline Forage intake $(\mathrm{kg})$ & $1792(15)$ & $1772(16)$ & $1861(32)$ & $1851(33)$ & $1539(137)$ & $1512(140)$ \\
\hline Concentrate intake (kg/calf) & $392(3)$ & $392(3)$ & $411(25)$ & $413(25)$ & $626(103)$ & $635(106)$ \\
\hline Grass DM yield $\left(\mathrm{tha}^{-1}\right)$ & $7.0(1.1)$ & $7.6(1.1)$ & $7.3(0.6)$ & $7.85(0.6)$ & $4.2(1.2)$ & $4.4(1.2)$ \\
\hline Severe stress $\left(\mathrm{hy}^{-1}\right)$ & $552(75)$ & $636(79)$ & $145(44)$ & $188(52)$ & $394(59)$ & $459(61)$ \\
\hline Gross margin ( $(/$ calf $)$ & $220(9)$ & $219(5)$ & $230(10)$ & $229(8)$ & $122(56)$ & $119(556)$ \\
\hline
\end{tabular}



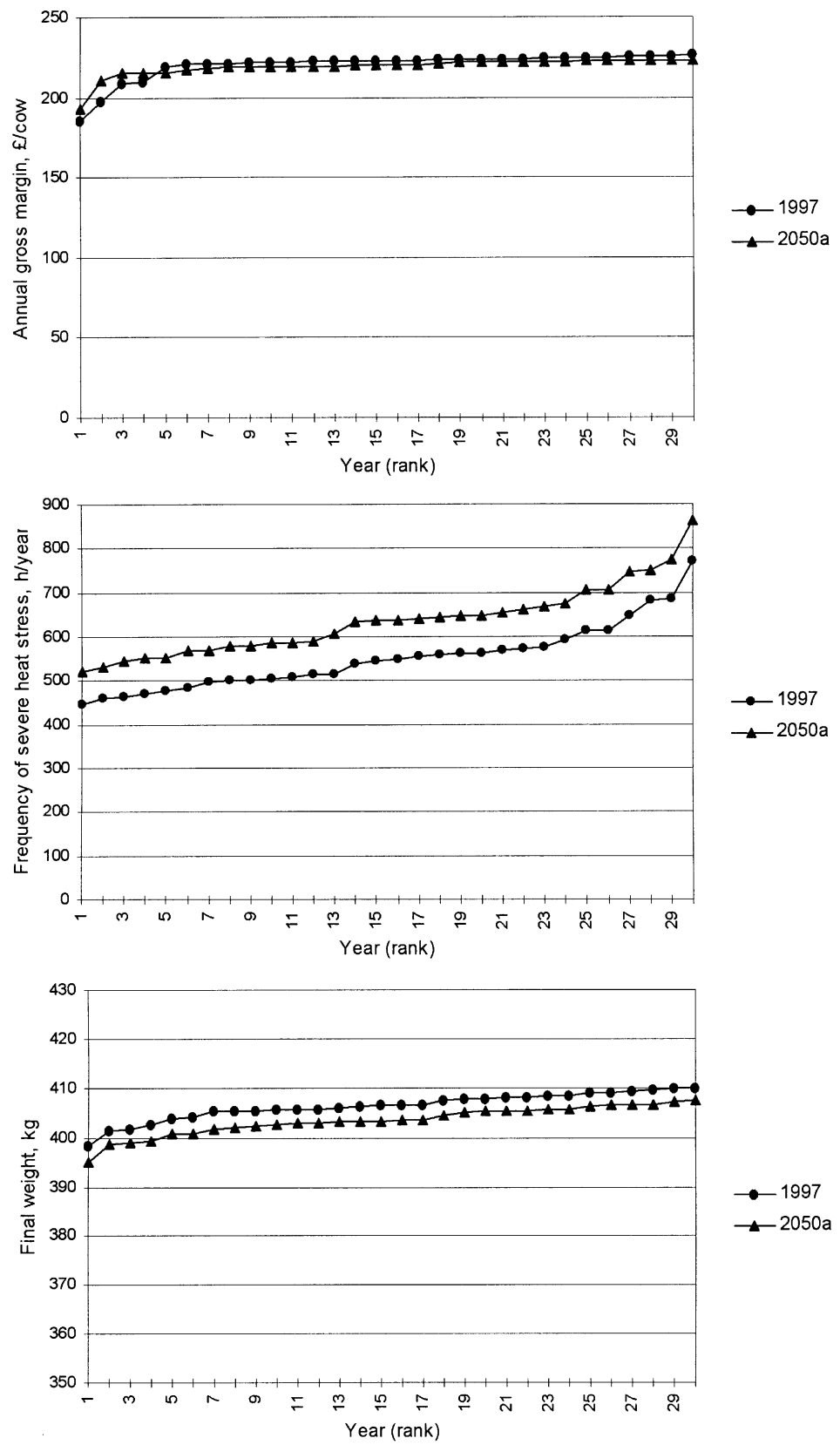

Fig. 4 Results of beef cattle simulation for 30 years at Boxworth, comparing baseline (1997) and modified (2050 IS92a) climates, ranked by the dependent variable: (a) Gross margin, (b) Frequency of severe heat stress, and (c) Final weight. $\bullet, 1997 ; \mathbf{\Lambda}, 2050 a$.

The measures of heat stress used here are indicators of changes in the physiological state of the animals. Some, for example panting, can be observed but others cannot. There are no field data with which to make comparisons, so the present levels are unknown. We proceed on the assumption that present levels are tolerable, but that substantial increases would be unacceptable. This is certainly the case for broilers, where mortality rates already increase during warm summers.
Despite these limitations, the baseline results do show realistic patterns, as shown by the comparison between the sites. For all of the grass-based enterprises, Cheshire, one of the largest dairy and beef producing regions, shows the highest productivity, resulting from high grass yields. Pwllpeiran, currently a marginal area, has the lowest productivity, but continues to be used for less intensive livestock production because it is unsuitable for other enterprises. Although Boxworth achieves fairly 

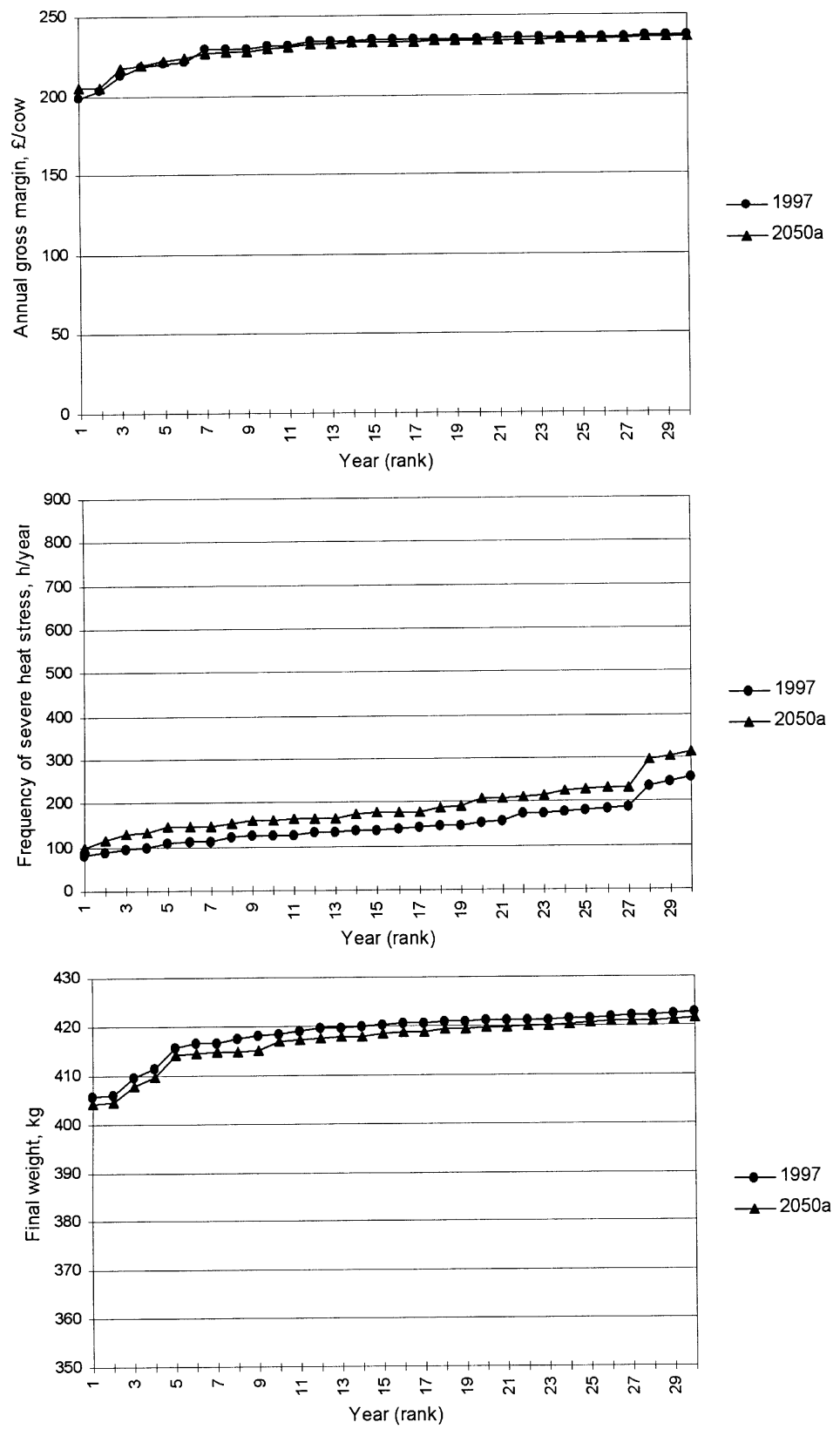

Fig. 5 Results of beef cattle simulation for 30 years at Cheshire, comparing baseline (1997) and modified (2050 IS92a) climates, ranked by the dependent variable: (a) Gross margin, (b) Frequency of severe heat stress, and (c) Final weight. $\bullet, 1997 ; \mathbf{\Lambda}, 2050$ a.

high productivity and profitability, the warmer summer climate results in higher levels of stress.

All the results are shown as means and standard deviations, but these should not be used for conventional significance tests for two reasons. First, the data are the results of deterministic models acting on data generated by stochastic weather generators, so they have unusual statistical properties. Secondly, there are dependencies between years in the different scenarios, invalidating the independence assumptions on which conventional analyses are based. In general, the results obtained actually have greater significance than would be indicated by hypothesis testing, because a change in the mean value is an indication of a change in the whole distribution. Thus, for example, a $20 \%$ increase in the mean frequency of heat stress with no change in the variance also implies a $20 \%$ increase in the upper quartile, and so on.

\section{Grass production}

The grass crop is fundamental to the three ruminant production systems considered, so to avoid repetition, 

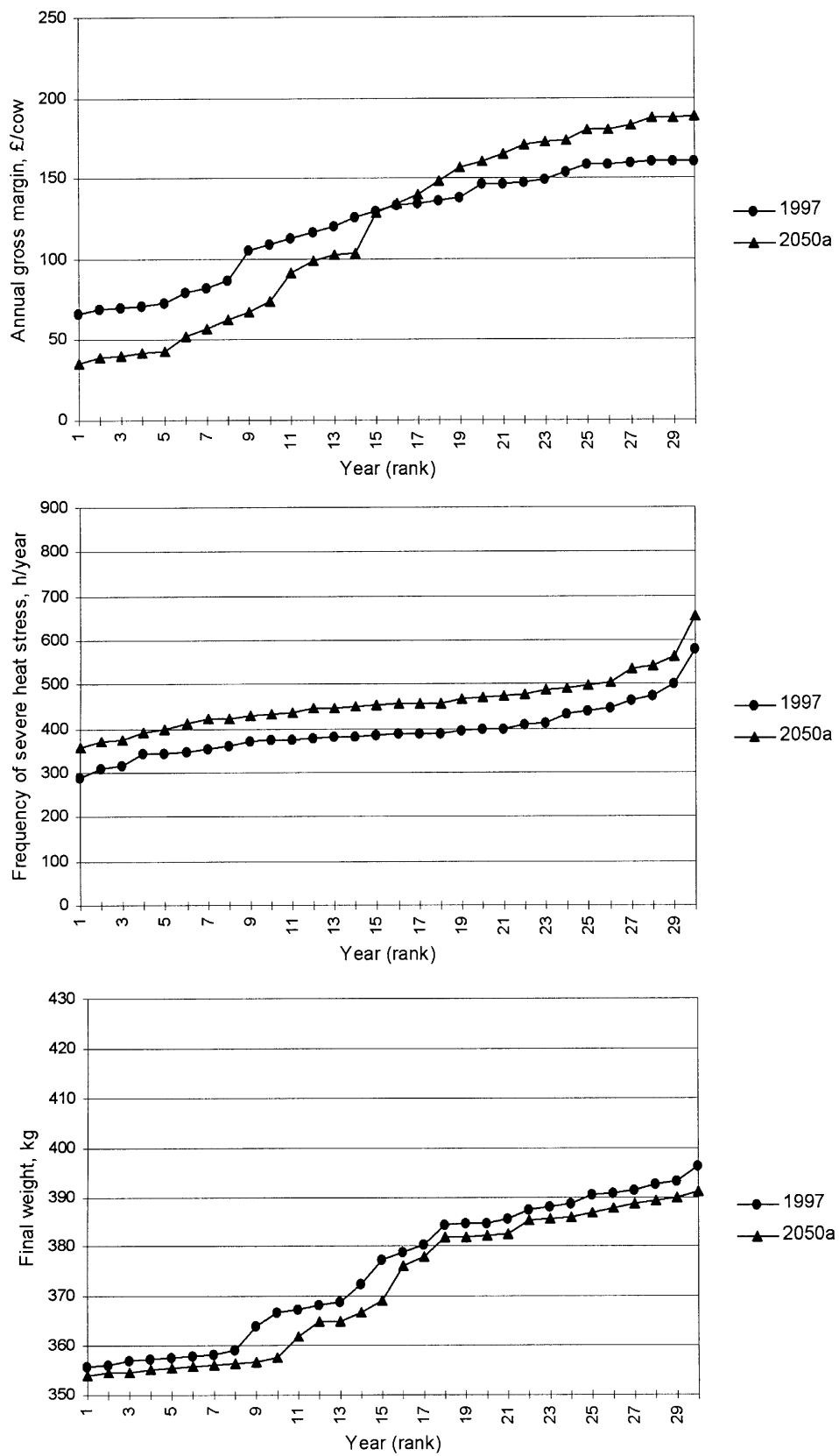

Fig. 6 Results of beef cattle simulation for 30 years at Pwllpeiron, comparing baseline (1997) and modified (2050 IS92a) climates, ranked by the dependent variable: (a) Gross margin, (b) Frequency of severe heat stress, and (c) Final weight. $\bullet, 1997 ; \mathbf{\Lambda}, 2050 \mathrm{a}$.

some of the common issues will be discussed here. Table 4 shows two measures related to the soil water status. For this analysis, but not in the model runs, the start of the grazing season was defined to be the first day after 1 March when the soil water fell to $10 \mathrm{~mm}$ below field capacity. The end was the first day after 31 August when it returned to that level. Upper bounds were set 60 days after those dates to handle exceptional cases. The other measure is the number of days for which the soil water content fell below the wilting point. This is the point at which water stress begins to limit grass growth, so it is a good measure of the effect of water on productivity and of the risk of drought.

Table 4 shows a strong site effect, with the dry lowland area (Boxworth) having the longest grazing season, but also the longest wilting duration, while the upland site has the shortest season and the shortest wilting duration. By these criteria, the grazing season at Pwllpeiran, which 
Table 7 Main input variables for dairy scenarios

\begin{tabular}{lll}
\hline & Boxworth & Cheshire \\
\hline Number of cows & 100 & 120 \\
Duration of model run (d) & 475 & 475 \\
Initial liveweight $(\mathrm{kg})$ & 600 & 600 \\
Target liveweight $(\mathrm{kg})$ & 660 & 660 \\
Total grass area (ha) & 60 & 60 \\
Fertiliser applied $\left(\mathrm{kgNha}^{-1}\right)$ & 400 & 400 \\
\hline
\end{tabular}

has very high rainfall, was frequently the shortest period allowed by the analysis, and turnout never occurred before the latest possible date. The criteria used are probably too strict for the less intensive farming practised in such areas.

The effect of climate change on these measures is minimal. The one substantial change shown, in the minimum grazing season for Boxworth, is the consequence of a very small change in soil moisture content causing it to reach the end of season threshold much later. The increase in rainfall predicted for all three regions in IS92a is offset by increased evapotranspiration caused by the increased temperature. These results are counterintuitive, but can be explained by examination of the weather data. The climate predictions derived from the IS92 scenarios as described above, show an increase in summer precipitation of up to $8 \%$. No data were available on the likely frequency of prolonged dry spells, so these could not be included.

The results for grass yield have been presented in the sections for the two cattle enterprises. They show yield increases of about $9 \%$ at Boxworth, $7 \%$ in Cheshire and $5 \%$ at Pwllpeiran, which bring the yields at Boxworth to the level of present yields in Cheshire. The increases in yield are the result of having a temperature rise without a significant change in water stress. Figure 3 shows how the distribution of yields changes, illustrating that a small increase in the mean yield represents a significant
Table 9 Main input variables for sheep scenarios

\begin{tabular}{llll}
\hline & Boxworth & Cheshire & Pwllpeiran \\
\hline Number of ewes & 100 & 100 & 100 \\
Duration of model run (d) & 365 & 365 & 365 \\
Age of lambs at slaughter (d) & 275 & 275 & 275 \\
Initial ewe liveweight $(\mathrm{kg})$ & 75 & 75 & 75 \\
Target ewe liveweight $(\mathrm{kg})$ & 75 & 75 & 75 \\
Total grass area (ha) & 12 & 12 & 12 \\
Fertiliser applied (kgNha & 100 & 100 & 100 \\
\hline
\end{tabular}

increase in the frequency of high yields. Previous studies (Armstrong \& Castle, 1995; Armstrong et al. 1995) have indicated that these increases in yield will be concentrated in the early part of the growing season.

The direct fertilization of grass production by the increase in $\mathrm{CO}_{2}$ concentration is likely to reinforce the observation that climate change will lead to an increase in total grass growth, an observation supported by experimental evidence (e.g. Jones etal. 1996; Schapendonk et al. 1996; Warwick et al. 1998). However, existing models (e.g. Stockle et al. 1992) would apply the same rate of change to all locations and all seasons within the UK, and so just change the absolute amount of grass grown; but have no effect on the relative rates of growth between sites or within years.

\section{Beef calves}

The beef enterprise was simulated for all three sites (Tables 5 and 6, Figs 4, 5 and 6), though the stocking rate at Pwllpeiran was lower that at the other two because of the lower carrying capacity of grassland in upland areas. Even so, the target weight was rarely achieved at Pwllpeiran. The results from this site also exhibited much greater variability than the others. Figure6(c) shows that the variation in weight is distributed uniformly across the full range, in contrast with

Table 8 Performance measures for dairy scenarios [mean (SD)]

\begin{tabular}{|c|c|c|c|c|}
\hline & \multicolumn{2}{|l|}{ Boxworth } & \multicolumn{2}{|l|}{ Cheshire } \\
\hline & Baseline & IS92a & Baseline & IS92a \\
\hline Milk yield (kg) & $5423(47)$ & $5374(49)$ & 5799 (3) & $5764(35)$ \\
\hline Final weight (kg) & $670(1)$ & $669(1)$ & $677(6)$ & $676(6)$ \\
\hline Forage intake $(\mathrm{kg})$ & $4891(17)$ & $4859(17)$ & $5309(184)$ & $5281(183)$ \\
\hline Concentrate intake $(\mathrm{kg})$ & $1257(16)$ & $1408(111)$ & $1059(169)$ & $1064(168)$ \\
\hline Grass DM yield $\left(\mathrm{tha}^{-1}\right)$ & $9.9(1.4)$ & $10.7(1.4)$ & $10.6(0.8)$ & $11.3(0.8)$ \\
\hline Severe stress $\left(\mathrm{hy}^{-1}\right)$ & $1262(105)$ & $1408(111)$ & $411(63)$ & $494(68)$ \\
\hline Gross margin $(£ /$ cow $)$ & $992(55)$ & $1010(51)$ & 1077 (37) & $1102(38)$ \\
\hline
\end{tabular}



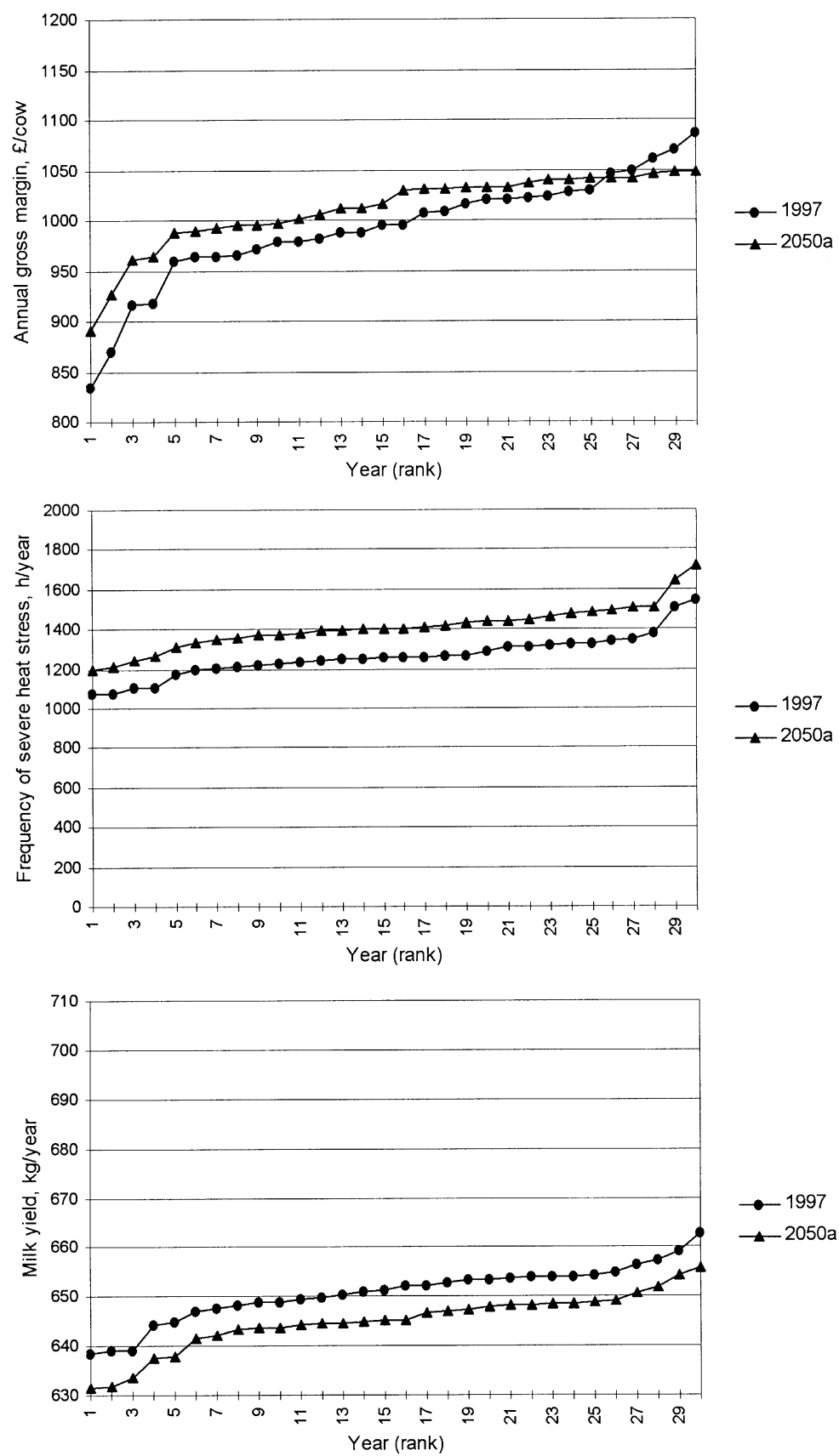

Fig. 7 Results of dairy cow simulation for 30 years at Boxworth, comparing baseline (1997) and modified (2050 IS92a) climates, ranked by the dependent variable: (a) Gross margin, (b) Frequency of severe heat stress, and (c) Final weight. $\bullet, 1997 ; \mathbf{\Lambda}, 2050 \mathrm{a}$.

Cheshire (Fig. 5c) where a few poor years accounted for most of the variation. The two lowland sites gave generally similar results, although the grass yield and other production variables were higher in Cheshire, as would be expected from present patterns of land use. There were slight increases in grass production of up to $9 \%$ under the modified scenario, as a result of the increased temperatures. These reduced the total con- sumption of buffer feed by over half at both lowland sites.

The frequency of heat stress increased by only about $15 \%$ at Boxworth and Pwllpeiran, but by $30 \%$ in Cheshire. However, this large relative increase was a result of the very low baseline level of stress at this site, and the total remained much lower than the baseline level for Boxworth. The higher values for Pwllpeiran, 

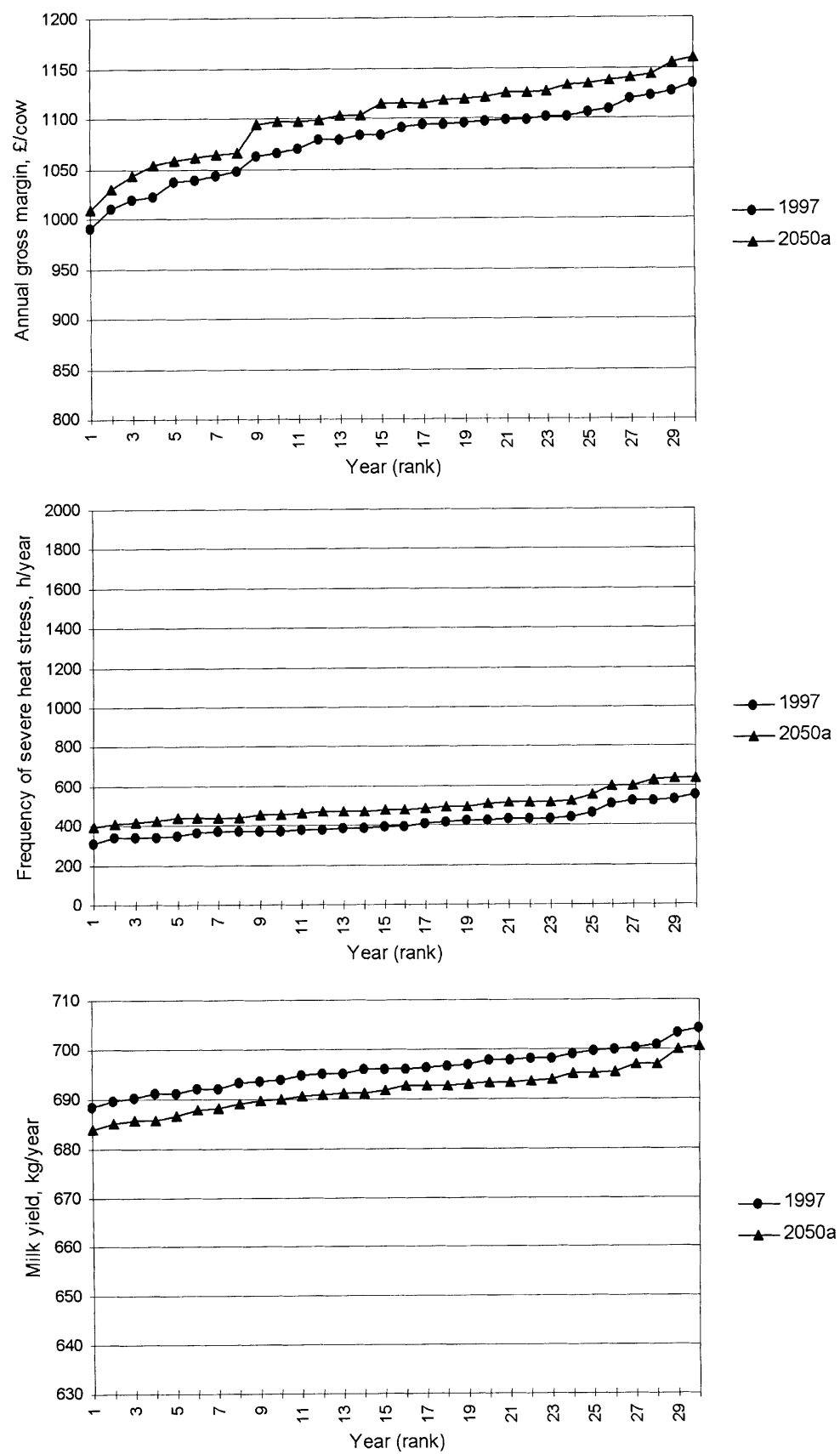

Fig. 8 Results of dairy cow simulation for 30 years at Cheshire comparing baseline (1997) and modified (2050 IS92a) climates, ranked by the dependent variable: a) Gross margin, (b) Frequency of severe heat stress, and (c) Final weight. $\bullet, 1997 ; \mathbf{\Lambda}, 2050$ a.

despite slightly lower temperatures than Cheshire, result from the smaller size of the animals, and hence reduced surface area for heat dissipation. The effects of the increases in stress on overall intake and growth were very small, because prolonged stress is required to produce a significant reduction. The resulting changes in mean gross margin were small, but there was a clear difference in the pattern between Pwllpeiran (Fig. 6a) and the other sites (Figs $4 a$ and 5a). The increase in variability under the changed climate causes the lines to cross in the middle of the range, which represents an increase in the riskiness of the enterprise. At the other two sites there are only a few poor years and very little difference between the scenarios.

In general, we conclude that the expected changes in climate are well within the calves' range of natural adaptation, especially outside the south-east, and are unlikely to cause serious problems of stress. The model 
Table 10 Performance measures for sheep scenarios [mean (SD)]

\begin{tabular}{|c|c|c|c|c|c|c|}
\hline & \multicolumn{2}{|l|}{ Boxworth } & \multicolumn{2}{|l|}{ Cheshire } & \multicolumn{2}{|c|}{ Pwllpeiran } \\
\hline & Baseline & IS92a & Baseline & IS92a & Baseline & IS92a \\
\hline Final weight (kg) & $76.8(6.5)$ & $71.8(7.4)$ & $91(4.0)$ & $87.5(5)$ & $80.8(5.9)$ & $76.3(6.8)$ \\
\hline Forage intake (kg) & $538(3)$ & $536(3)$ & $547(2)$ & $545(3)$ & $543(3)$ & $542(3)$ \\
\hline Final lamb weight (kg) & $45.3(1.0)$ & $44.3(1.1)$ & $47.6(0.6)$ & $47.1(0.7)$ & $46.2(0.8)$ & $45.5(1.0)$ \\
\hline Severe ewe stress $\left(\mathrm{hy}^{-1}\right)$ & $784(88)$ & $933(99)$ & $304(58)$ & $385(70)$ & $553(77)$ & $670(84)$ \\
\hline Severe lamb stress $\left(\mathrm{hy}^{-1}\right)$ & $126(40)$ & $182(45)$ & $16(12)$ & $26(15)$ & $33(17)$ & $51(24)$ \\
\hline Gross margin (£/ewe) & $46.6(2.7)$ & $46.3(2.2)$ & $45.2(5.7)$ & $45.6(5.2)$ & 44.8 (7.7) & $44.3(7.1)$ \\
\hline
\end{tabular}

assumes that the animals are in open fields, with no shade, so the peak stress could be reduced by the provision of shade by trees or structures. There was no change in the relative suitability of the three regions for this enterprise.

\section{Dairy cows}

The dairy enterprise was simulated for the Boxworth and Cheshire sites (Tables 7 and 8, Figs 7 and 8). The grass at Pwllpeiran is generally not of high enough quality to consider grazing dairy cows there and the topography is unsuitable. The grass yield and quality were higher in Cheshire than at Boxworth and consequently stocking rates of 1.67 cows ha $^{-1}$ and 2 cowsha $^{-1}$ were used for Boxworth and Cheshire, respectively. In general, the results of the dairy cow simulation runs agreed with those for the beef calves. The two sites give similar results, with the grass yield, gross margin and other production variables higher for Cheshire, as expected. In Cheshire, the gross margins for 2050 dominate (Fig. 8a). At Boxworth this is true for most of the range, although the highest margins occur in a few years of the present climate (Fig. 7a). The mean grass yield increased by about $7 \%$, indicating the potential for slightly higher stocking rates to be supported. This was reflected in a reduction of about $30 \%$ in buffer feeding at both sites.

The mean milk yield, final weight and forage intake decreased slightly and Figs 7(c) and 8(c) show that yield under the baseline climate dominates the changed climate.

The predicted heat stress incidence Cheshire was about a third of that at Boxworth. This was the result of a lower average temperature in Cheshire, with many fewer temperatures in the $20-30{ }^{\circ} \mathrm{C}$ range. The frequency of heat stress increased by $10 \%$ and $20 \%$ for Boxworth and Cheshire, respectively. At both sites (Figs $7 b$ and $8 b$ ) the 2050 results dominate.

The dairy cow should have no major problems adapting to the expected changes in climate, although in warmer regions the cows may benefit from the provision of shade. The farmer may benefit from increases in grass production allowing higher stocking rates. There was no change in the relative suitability of Cheshire and Boxworth for dairy cows.

\section{Sheep}

The sheep enterprise was simulated for all three sites with the same stocking rate for each (Tables 9 and 10). As before the influence of the different climate scenarios on the gross margin and other factors was marginal.

For all three sites the incidence of heat stress on the ewe increased by approximately $20 \%$. The frequency of the heat stress for the lamb was less severe than for the ewe and was only $16 \mathrm{~h}$ per year for the baseline climate in Cheshire. However, this stress frequency almost doubled under the climate change scenario. Thus, on certain days, heat stress may cause a problem for the lamb. The frequency of heat stress was largest at Boxworth and least in Cheshire, as for the beef calf.

The increase in heat stress caused a marginal reduction in forage intake and final lamb weight. It also resulted in a $6 \%$ reduction in the final weight of the ewe.

In conclusion, climate change should present no serious adaptation problems for the lamb or ewe. Furthermore the relative suitability of the three regions for sheep farming remains unchanged. However, more provision should be made to protect the animals from direct sun on hot days.

\section{Discussion}

\section{Limitations of the models and the study}

The models developed for this study are the first to attempt to combine the four processes of crop production, animal feeding, animal thermal balance and building environment into integrated models. They have 
shown the potential of such models for use in studies of farming systems, but have also shown the difficulty of combining models developed separately for a variety of purposes into system models capable of representing farming practice realistically.

The grass model used, like most others, was originally designed to predict the production of conserved forage. The interaction with grazing animals requires a more dynamic modelling approach than the one used in this project.

This study raised many issues for further research. Experience with other models shows that it should be possible to use the results of farming system trials and observations of current practice to tune the models, in order to improve the realism of the results and increase the level of confidence in their application to climate change or other areas of policy evaluation. Further investigation of management responses to climate change, such as change in stocking rate, production levels and ventilation, are also needed.

\section{Conclusions}

1 Ruminants at grass or in naturally ventilated buildings should be able to adapt easily to the expected changes in climate and there is no evidence of change in the relative suitability of the areas considered for the major types of livestock enterprises.

2 Assuming that there is no change in the relative prices of inputs and outputs, the net change in profitability is likely to be small but positive.

3 The results suggest that climate change would result in a modest increase in grass production. Although the present model did not fully exploit this, because it used fixed stocking rates, there was a reduction in the frequency with which buffer feeding was required for both cattle enterprises. It is anticipated that increased stocking rates to make use of this increased production will be possible.

\section{Acknowledgements}

This project was funded by the UK Ministry of Agriculture, Fisheries and Food under the Impacts of Climate Change research programme, as contract CSA2523/CC0315. Some of the weather data used in the development and validation of the models used in this project were provided by the Meteorological Office, Bracknell. SPECTRE was provided by the Climate Research Unit (CRU) at the University of East Anglia, and we would like to thank Dr David Viner of CRU for his advice and assistance in the interpretation of the climatic scenarios. We would also like to thank Anton de Baets, who assisted in the analysis of the results while on placement at Silsoe Research Institute from Wageningen Agricultural University.

\section{References}

AFRC (1993) Energy and Protein Requirements of Ruminants. An advisory manual prepared by the AFRC Technical Committee on Responses to Nutrients. CAB International, Wallingford, UK.

Alexander G (1974) Heat loss from sheep. In: Heat Loss from Animals and Man Proceedings of the 20th Eastern School in Agricultural Science, University of Nottingham, (eds Monteith JL, Mount LE), pp. 173-203. Butterworths, London.

Allen-Diaz B (ed.) (1996) Rangelands in a changing climate: Impacts, Adaptations, and mitigation. In: Climate Change 1995: Impacts, Adaptations and Mitigation of Climate Change: ScientificTechnical Analyses Contribution of Working Group II to the Second Assessment Report of the Intergovernmental Panel on Climate Change (eds Watson RT et al.), pp. 131-158. Cambridge University Press, Cambridge.

Armstrong AC (1996) The impact of climate change on grassland production and utilisation. Aspects of Applied Biology, 45, 7984.

Armstrong AC, Castle DA (1992) Potential impacts of climate change on the productivity of drained grassland. Grass and Forage Science, 47 (50-61), 1992.

Armstrong AC, Castle DA (1995) Potential effects of climate changes on agricultural production and the hydrology of drained grassland in the UK. In: Geomorphology and Land Management in a Changing Environment (eds McGregor DF, Thompson DA), pp. 139-151.Wiley, Chichester.

Armstrong AC, Garwood EA (1991) Hydrological consequences of artificial drainage of grassland. Hydrological Processes, 5, 157-174.

Armstrong AC, Castle DA, Tyson KC (1995) SWARD: a model of grass growth and the economic utilisation of grassland. In: Crop-Water-Simulation Models in Practice (eds Pereira LS et al.), pp. 189-197. Wageningen Pers, Wageningen.

Barrow E, Hulme E, Jiang T (1994) SPECTRE: Spatial and Point Estimates of Climate Change due to Transient Emissions. Climatic Research Unit, University of East Anglia, Norwich.

Bianca W (1965) Reviews of the progress of dairy science. Section A: Physiology. Cattle in a hot environment. Journal of Dairy Research, 32, 291-345.

Blaxter KL, Graham NMcC, Wainman FW, Armstrong DG (1959) Environmental temperature, energy metabolism and heat regulation in sheep. II - The partition of heat losses in closely clipped sheep. Journal of Agricultural Science, 52, 25-49.

Brignall AP, Rounsevell MDA (1995) Land evaluation modelling to assess the effects of climate change on winter wheat potential in England and Wales. Journal of Agricultural Science, Cambridge, 124, 159-172.

Bruce JM (1974) Wind Tunnel Investigation 4 - a model livestock building. Internal Report. Scottish Farm Buildings Investigation Unit, Aberdeen.

Bruce JM (1974) Wind Tunnel Investigation 4 - a model livestock building. Internal Report. Scottish Farm Buildings Investigation Unit, Aberdeen.

Bruce JM, Clark JJ (1979) Models of heat production and critical temperature for growing pigs. Animal Production, 28, 353-369.

Charles DR (1981) Practical ventilation and temperature control for poultry. In: Environmental Aspects of Housing for Animal Production (ed. Clark JA), pp. 183-197. Butterworths, London. Clapperton JL, Joyce JP, Blaxter KL (1965) Estimates of the contribution of solar radiation to the thermal exchanges of 
sheep at a latitude of 55N. Journal of Agricultural Science, 64, $37-49$.

Close WH (1987) The influence of the thermal environment on the productivity of pigs. In: Pig Housing and the Environment (eds Smith AT, Lawrence TLJ). Occasional Publication No 11 of the British Society of Animal Production. British Society of Animal Production, Edinburgh.

Cooper K, Parsons DP, Demmers T (1998) Thermal balance models of livestock buildings for use in climate change studies. Journal of Agricultural Engineering Research, 69, 43-52.

Dowle K, Armstrong AC (1990) A model for investment appraisal of grassland drainage schemes on farms in the U.K. Agricultural Water Management, 18, 101-120.

Edelsten PR, Corrall AJ (1979) Regression models to predict herbage production and digestibility in a non-regular sequence of cuts. Journal of Agricultural Science, Cambridge, 92, 575-585.

Favis-Mortlock D (1995) The use of synthetic weather for soil erosion modelling. In: Geomorphology and Land Management in a Changing Environment (eds McGregor DFM, Thompson DA), pp. 265-282. Wiley, Chichester.

Gates DM (1980) Biophysical Ecology. Springer, New York.

Glass MH, Jacob RH (1991) Losses of sheep following adverse weather after shearing. Australian Veterinary Journal, 69 (6), 142-143.

Hales JRS, Webster MED (1967) Respiratory function during thermal tachypnoea in sheep. Journal of Physiology, 190, 241260.

Hallett SH, Thanigasalam P, Hollis J (1992) SEISMIC: an integrated spatial information system for managing the impact of chemicals. In: Environmental Modelling - the Next Ten Years (eds Stebbing ARD et al.), pp. 40-49. SETAC-UK, Liverpool.

Harrison PA (1996) Modelling the effects of climate change on wheat productivity in Europe. Annals of Applied Biology, 45, $41-48$.

Higgins KP, Dodd VA (1989) A Model of the Bioclimatic Value of Shelter to Beef Cattle. Journal of Agricultural Engineering Research, 42 (3), 149-164.

Hollis JM, Hallett SH, Keay CA (1993) The development and application of an integrated database for modelling the environmental fate of herbicides. Brighton Crop Protection Conference - Weeds, 1993, 1355-1364.

IPCC (1992) Climate Change 1992: the Supplementary Report to the IPCC Scientific Assessment. Cambridge University Press. Cambridge, 200pp.

Jones MB, Jongen M, Garvey L, Baxter R (1996) The physiological responses of a European grassland species to elevated $\mathrm{CO}_{2}$. Annals of Applied Biology, 45, 155-161.

Kimball BA (1983) Carbon-dioxide and agricultural yield: an assemblage and analysis of 430 prior observations. Agronomy Journal, 75, 779-788.

Matalas NC (1967) Mathematical assessment of synthetic hydrology. Water Resources Research, 3, 937-945.

McArthur AJ (1987) Thermal Interaction between animal and microclimate: a Comprehensive model. Journal of Theoretical Biology, 126, 203-238.

McArthur AJ (1991) Thermal radiation exchange, convection and the storage of latent heat in animal coats. Agricultural and Forest Meteorology, 53 (4), 325-336.

McArthur AJ, Monteith JL (1980) Air movement and heat loss from sheep. 1. Boundary layer insulation of a model sheep, with and without fleece. Proceedings of the Royal Society of London B, 209, 187-208.

Melillo JM, Callaghan TV, Woodward FI, Salti E, Sinha SK (1990) Effects on ecosystems. In: Climate Change: the IPCC Scientific Assessment (eds Houghton JT et al.), pp. 283-310. Cambridge University Press, Cambridge.

Mount LE (1979) Adaptation to Thermal Environment - Man and his Productive Animals. Edward Arnold, London.

Mount LE, Brown D (1982) The use of meteorological records in estimating the effects of weather on sensible heat loss from sheep. Agricultural Meteorology, 27, 241-255.

Owen JE (1994) Structures and materials. In: Livestock Housing (eds Wathes CM, Charles DR), pp. 183-246. Commonwealth Agricultural Bureaux, Oxford.

Parry ML, Carter TR, Konijn NT (eds) (1998) The Impact of Climatic Variations on Agriculture, Vol 1: Assessments in Cool Temperate and Cold Regions. Kluwer, Dordrecht.

Parsons KC (1993) Human Thermal Environments. Taylor \& Francis, London.

Parsons AJ, Johnson IR (1985) The physiology of grass growth on grazing. In: Grazing (ed. Frame J), pp. 3-13. Occasional Symposium No 19. British Grassland Society, Hurley.

Richardson CW, Nicks AD (1990) Weather generator description. In: EPIC - Erosion/ Productivity Impact Calculator: 1 Model Documentation (eds Sharpley AN, Williams JR). US Department of Agriculture Technical Bulletin no. 1768, US Department of Agriculture, Temple, Texas.

Richardson CW (1981) Stochastic simulation of daily precipitation, temperature, and solar radiation. Water Resources Research, 17, 182-190.

Ritzema HP (ed. in chief) (1994) Drainage Principles and Applications, 2nd edn. ILRI Publication 16. International Institute for Land Reclamation and Improvement, Wageningen.

Schapendonk AHMC, Dijkstra P, Groenwold J, Pot CS, van de Geijn SC (1996) Implications of elevated carbon dioxide concentration in Lolium perenne L. swards. Aspects of Applied Biology, 45, 31-40.

Senft RL, Rittenhouse LR (1985) A model of thermal acclimation in cattle. Journal of Animal Science, 61, 297-306.

Sharpley AN, Williams JR (eds) (1990) EPIC - Erosion/ Productivity Impact Calculator: 1 Model Documentation. US Department of Agriculture Technical Bulletin no. 1768, US Department of Agriculture, Temple, Texas.

Stafford Smith DM, Noble IR, Jones GK (1985) A heat balance model for sheep and its use to predict shade-seeking behaviour in hot conditions. Journal of Applied Ecology, 22, 753-774.

Stockle CO, Williams JR, Rosenberg NJ, Jones CA (1992) A method for estimating the direct and climatic effects of rising atmospheric Carbon Dioxide on growth and yield of crops: part I - Modification of the EPIC model for climate change analysis. Agricultural Ecosystems, 38, 225-238.

Thompson GE (1973) Review of the progress of Dairy Science Climatic physiology of cattle. Journal of Dairy Research, 40, 441-473.

Turnpenny JR (1997) Potential impact of climate change on the energy balance of UK livestock. PhD thesis, University of Nottingham.

Turnpenny JR, McArthur AJ, Clark JA, Wathes CM (2000a) 
112 D. J. PARSONS et al.

Thermal balance model of livestock. 1. A parsimonious model. Agricultural and Forest Meteorology, 101, 15-27.

Turnpenny JR, McArthur AJ, Clark JA, Wathes CM (2000b) Thermal balance model of livestock. 2. Applications of a parsimonious model. Agricultural and Forest Meteorology, 101, 29-52.

Turnpenny JR, Parsons DJ, Armstrong AL, Clark JA, Cooper K, Matthews AM (2000c) Integrated models of livestock systems for climate change studies. 2. Intensive systems. Global Change Biology, 7, in press.

Tyson KC, Hawkins JMB, Stone AC (1993) Final Report on the AFRC-ADAS Drainage Experiment 1982-93. AFRC Institute of
Grassland and Environmental Research, North Wyke Research Station, Okehampton. 33pp.

UKCCIRC (1996) Review of the potential effects of climate change in the United Kingdom. Report of the United Kingdom Climite Change Impacts Reviews Group. HMSO; London, $247 \mathrm{pp}$.

Warwick KR, Taylor G, Blum H (1998) Biomass and compositional changes occur in chalk grassland turves exposed to elevated $\mathrm{CO}_{2}$ for two seasons in FACE. Global Change Biology, 4, 375-385.

Wood PDP (1969) Factors affecting the shape of the lactation curve in cattle. Animal Production, 11(3), 307-316. 